\section{Can lefties study be right?}

\section{Washington}

A STARTLing study that found that left-handers die an average of nine years earlier than right-handers has triggered a sharp debate among psychologists and epidemiologists. Although most researchers are willing to accept the possibility that, for both physiological and environmental reasons, righthanders do indeed live longer than lefthanders, few can believe that the difference in life expectancy could be so great.

"If you think about it, this is a bigger difference than if you smoke two packs a day," said Alan Searleman, a psychologist at St Lawrence University in Canton, New York, who has studied differences between rightand left-handed people. "If it were true, you'd think that over the years it would have been noticed."

But until this month, the only evidence of a disparity in life expectancies between the two groups had appeared three years ago in Nature $(333,213 ; 1988)$. In that report, psychologists Stanley Coren of the University of British Columbia and Diane Halpern of California State University had studied the

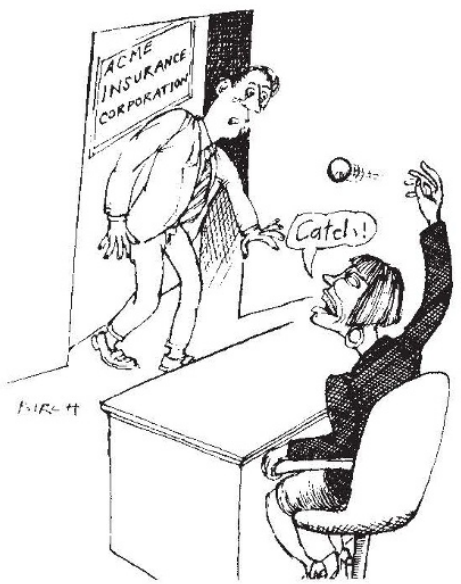

life expectancies of professional baseball players and discovered a difference of eight months in average lifetimes.

On 4 April, Coren and Halpern reported a much stronger result in the New England Journal of Medicine $(324,998 ; 1991)$. They had determined the handedness of 987 people who died in two southern California counties, defining as right-handed all those who wrote, drew and threw a ball with their right hands, while left-handers and mixedhanders were lumped together as 'non-righthanded'. When Coren and Halpern calculated that average age of death for the two groups, they found it to be 75 years for righthanders and 66 among the non-right-handers. The pattern held up when the cases were divided by sex: males 72 versus 62 , and females 78 versus 73 .

The idea that right-handers may, on average, live longer than left-handers is not particularly surprising, say those in the field. Previous studies have found, for instance, that left-handers are more prone to autoim- mune diseases and are more likely to have been born prematurely or to have been lowbirth-weight babies.

Other work, including an earlier study by Coren, has suggested that left-handers are more likely to have accidents. The disparity in accident rates may arise, Halpern and Coren suggest, because life in an environment designed for right-handers may be slightly more hazardous for left-handers.

Coren and Halpern's paper has received extensive coverage in the US press, and has sparked concern over the possible public policy implications, if indeed the results are replicated. Would insurance companies, for instance, be justified in charging left-handers higher rates for medical and life insurance?

Meanwhile, various aspects of the CorenHalpern study have been questioned. One

\section{Washington}

APRIL marks the beginning of the rainy season in the Sahel region of sub-Saharan Africa, and the start of another critical period in determining the future food prospects in this famine-prone area. Because of a poor harvest last year and a continuing civil war, Sudan is the most vulnerable country in the region.

Now, a technological crystal ball is predicting that famine will probably strike that country hard. The prophecy is based on data gathered by the Famine Early Warning System (FEWS), a project that anticipates food needs in this region of Africa using satellite and on-site reports. FEWS, which has been operating since June 1989 , tracks weather as well as political and economic conditions, and enables scientists to predict areas that may be badly hit in the coming season.

But hard experience teaches that prediction does not equal prevention. With all the advance warning and high technology of the FEWS system, food aid is still sometimes difficult to get into the countries that need it the most. For example, FEWS predicted last year that Sudan would be a trouble spot and mobilized food aid to avert disaster, but poor transportation and lack of government cooperation in the country severely hampered relief efforts. "The biggest problem in the Sudan is the government's not wanting to admit that there's a problem," says Marian Mitchell of the FEWS project. Conditions are expected to worsen, and up to nine million people are at risk of starvation.

A NASA Advanced Very High Resolution Radiometer satellite estimates the vegetation, or greenness of the ground, by scanning the Earth with infrared and nearinfrared frequencies of light to gauge the amount of chlorophyll. Generally, Mitchell says, rain in an area shows up about 10-20 consistent observation is that natural lefthanders growing up early in the twentieth century may have been coerced into using their right hands - which would make it appear now as if the older left-handers had died off, when in reality they had simply turned into right-handers. Coren argues, however, that several studies have shown that the percentage of adults who are left-handed has not varied since the early $1900 \mathrm{~s}$, but has remained at about 10 per cent of the population. Searleman, in response, says that those conclusions depend on "spooky data" and should not be trusted.

The best way to settle the issue, everyone agrees, would be to have a large prospective study following a large cohort for a decade or more, recording deaths and their causes. Such a study would be both expensive and time-consuming, but until it is done, the true risk of being left-handed will remain a subject of debate.

Robert Pool

\title{
Spotting famine from space
}

days later as in a greener landscape detectable by the satellite system.

Actual rainfall is measured at stations in each country, and the data are transmitted to FEWS every ten days. And field representatives monitor political and economic conditions in seven countries - Mauretania, Mali,
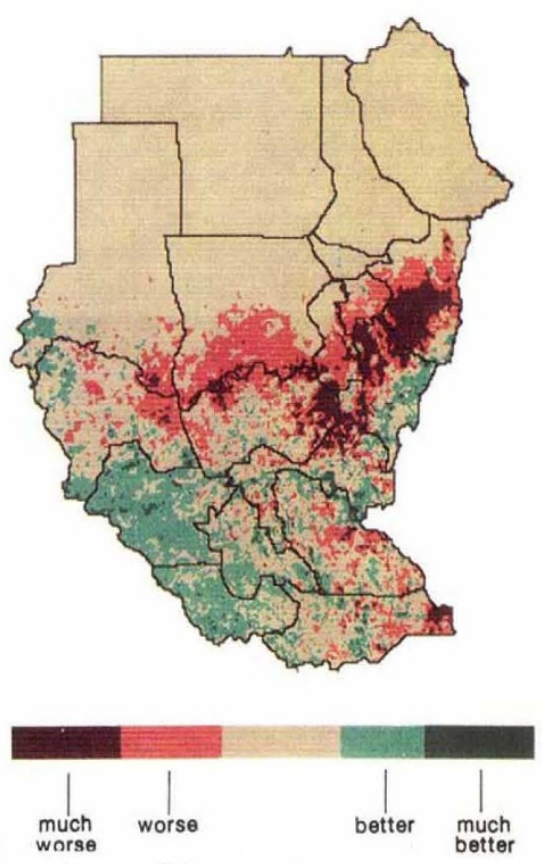

Drought conditions in Sudan as revealed by NASA's radiometer satellite.

Burkina, Niger, Chad, Sudan and Ethiopia. By combining these data investigators can estimate rainfall levels and the potential consequences to food crops. The results are published by FEWS every 10 days during the rainy season, which alert officials of the US Agency for International Development to potential crisis areas.

Diana Steele 